cần thiết để phát hiện sớm hạ kali máu. Bổ sung kali trong dịch bù là tối cần thiết để dự phòng hạ kali máu.

Phù não là môt biến chứng nguy hiểm của nhiễm toan ceton [4]. Đây không phải là một biến chứng phổ biến nhưng có thể để lại hậu quả nặng nề. Trẻ em hay gặp biến chứng này hơn so với người lớn. Các triệu chứng của phù não thường xuất hiện trong quá trình điều trị NTCT nhưng có thể xuất hiện trước khi bắt đầu điều trị.

\section{KẾT LUÂN}

Bệnh nhân được chẩn đoán ĐTĐ type 1 lần đầu ở Bệnh viện Nhi Trung ương có tỷ lệ NTCT cao. Nồng độ C-peptid dưới $1,1 \mathrm{ng} / \mathrm{ml}$, chẩn đoán nhầm, trì hoãn điều trị là các yêu tố gây gia tăng nguy cơ và mức độ NTCT. Suy thận cấp là biến chứng hay gặp trong NTCT.

\section{TÀI LIÊU THAM KHẢO}

1. Lee H.J., Yu H.W., Jung H.W., et al (2017). Factors Associated with the Presence and Severity of Diabetic Ketoacidosis at Diagnosis of Type 1 Diabetes in Korean Children and Adolescents. Journal Korean Medical Sciences, 32(2):303.

2. Mayer-Davis E.J., Kahkoska A.R., Jefferies C. et al (2018). ISPAD Clinical Practice Consensus Guidelines 2018: Definition, epidemiology, and classification of diabetes in children and adolescents. Pediatric Diabetes, 19, 7-19.

3. Usher-Smith J.A., Thompson M., Ercole A. et al (2012). Variation between countries in the frequency of diabetic ketoacidosis at first presentation of type 1 diabetes in children: a systematic review. Diabetologia, 55(11), 2878-2894.

4. Wolfsdorf J.I., Glaser N., Agus M., et al (2018). ISPAD Clinical Practice Consensus Guidelines 2018: Diabetic ketoacidosis and the hyperglycemic hyperosmolar state. Pediatric Diabetes, 19, 155-177.

5. Professional Practice Committee 2018.Standards of Medical Care in Diabetes2018.Diabetes Care, 41(Supplement 1), S3-S3.

6. Usher-Smith J.A., Thompson M.J., Sharp S.J. et al (2011). Factors associated with the presence of diabetic ketoacidosis at diagnosis of diabetes in children and young adults: a systematic review. BMJ, 343, d4092-d4092.

7. Varshney GA., Varshney D., Mehr $V$, et al (2015). Clinical profile and outcome of diabetic ketoacidosis in children at tertiary care hospital. Journal Evolution of Medical Dental Sciences, 4(31), 5329-5333.

8. Mohammed A.N (2015)Characteristics of pediatric diabetic ketoacidosis patients in Saudi Arabia.Saudi Medicine Journal, Vol. 36 (1).

9. Rosenbauer J (2002). Clinical characteristics and predictors of severe ketoacidosis at onset of type 1 diabetes mellitus in children in a North Rhine-Westphalian Region, Germany.Journal of Pediatric Endocrinology \& Metabolism, 15, 1137-1145.

\title{
SO SÁNH TỶ LÊ BIẾN CỐ CHẢY MÁU, TỶ LÊ BỎ THUỐC VÀ ẢNH HƯởNG TRÊN MỘT SỐ CHİ SỐ HÓA SINH MÁU GIỮA TICAGRELOR VỚI CLOPIDOGREL TRÊN BÊ̂NH NHÂNBI BÊ̂NH ĐộNG MẠCH CHI DƯỚI
}

\section{TÓM TẮT}

Hoàn cảnh nghiên cứu: Ticagrelor là môt thuốc kháng kết tập tiểu cầu qua cơ chế ức chế thuận nghịch thụ thể P2Y12. Ưu điểm của thuốc này là không phải chuyển hóa qua gan thành dạng có tác dung dược lý như clopidogrel. Nghiên cứu PLATO trên bểnh nhẩn bị hôi chứng động mạch vành cấp cho thây ticagrelor không những có hiệu quả hơn clopidogrel trong phòng ngừa biến cố tim mach mà thuốc này cũng không làm tăng các biến cố chảy máu. Do đó chúng tôi tiến hành nghiên cứu này trên đối tượng bệnh nhân bị BĐMCD để kiểm chứng xem tỷ lệ biến cố

\section{*Đại Học Y Dược Thái Binh \\ ** Dai Hoc Y Hà Nôi}

Chị trách nhiệm chính: Trần Xuân thủy

Email: bsxuanthuyytb@gmail.com

Ngày nhận bài: 28.12.2020

Ngày phản biên khoa học: 22.2.2021

Ngày duyệt bài: 2.3.2021

\section{Trần Xuân Thủy*, Đinh Thị Thu Hương**}

chảy máu, tỷ lệ bỏ thuốc, ảnh hưởng trên một số chỉ số hóa sinh máu của ticagrelor có thực sự tương đương với clopidogrel hay không? Phương pháp nghiển cứu: Nghiên cứu lâm sàng ngẫu nhiên có đối chứng trên 178 bệnh nhân bị BĐMCD: nhóm nghiên cứu dùng ticagrelor $90 \mathrm{mg} \times 2$ lần/ngày, nhóm chứng dùng clopidogrel $75 \mathrm{mg} / \mathrm{ngày}$. Thời gian theo dõi 18-36 tháng. Tiêu chí nghiên cứu là các biến cố mọi loại chảy máu, xuất huyết não, chảy máu gây tử vong, thời gian dùng thuốc trung bình, tỷ lệ bỏ thuốc và nồng độ một số chỉ số hóa sinh máu. Kết quả: Tỷ lệ mọi loại chảy máu ở nhóm nghiên cứu là 7,8\%; ở nhóm chứng là $6,8 \%$. Sự khác biêt là không có ý nghĩa thống kê với $p=0,79$. Tỷ lệ chảy máu phải truyền máu ở nhóm nghiên cứu là $1,1 \%$; ở nhóm chứng là $2,3 \%$ với $p=0,546$. Có 1 bệnh nhân xuất huyết não ở nhóm chứng. Chúng tôi không găp bênh nhân nào chảy máu gây tử vong ở 2 nhóm. Tỷ lệ bỏ thuốc ở nhóm nghiên cưuu là $12,4 \%$; ở nhóm chứng là $17 \%$, với OR $(\mathrm{CI} 95 \%)=1,46(0,63-3,38)$. Thời gian dùng thuốc trung bình của 2 nhóm khác biệt không có ý nghĩa với $p=0,96$. Nồng độ các chỉ số hóa sinh 
máu: creatinin, GOT, GPT, Bilirubin, glucose và huyết sắc tố ở hai nhóm khi kết thúc điêu trị khác biệt không có ý nghĩa với $p>0,05$. Kết luận: Tỷ lệ chảy máu, tỷ lệ bỏ thuốc và ảnh hưởng trên một số chỉ số hóa sinh máu của ticagrelor tương đương với clopidogrel trên bệnh nhân bị bệnh động mạch chi dưới.

Tư khóa: bệnh động mạch chi dưới, ticagrelor, clopidogrel.

\section{SUMMARY}

THE BLEEDING RATE, THE MEDICINE STOPED RATE AND THE EFFECT ON SOME BIOCHEMICAL BLOOD PARAMETERS OF TICAGRELOR IN COMPARE TO

\section{CLOPIDOGREL ON THE PATIENTS WITH}

\section{LOWER EXTREMITY ARTERY DISEASE}

Background: Ticagrelor is an antiplatelet drug through reversible inhibition of the $\mathrm{P} 2 \mathrm{Y} 12$ receptor. This drug do not have to metabolize by the live like clopidogel. On the patients with acute coronary syndrom in PLATO trial, ticagrelor is not only superior to clopidogrel in reduction of cardiovascular events, but it also does not increase the bleeding risks. So, we conducted this trial on the patient with lower extremity artery disease (PAD) to compare the bleeding risk, the medicine stoped rate and effect on some biochemical blood parameters of ticagrelor with clopidogrel. Subjects and Methods: In this clinical trial, we randomly assiqned 178 patients with PAD to receive monotherapy with ticaqrelor $(90 \mathrm{mg}$ twice daily) or clopidoqrel ( $75 \mathrm{mq}$ once daily). The end points were the bleeding rate, the cerebral hemorrhage rate, the medicine stoped rate, and concentration of some biochemical blood parameters. The time of follow-up was 18-36 months. Results: The bleeding rate in ticagrelor group was $7,8 \%$ v.s $6,8 \%$ in clopidogrel group with $\mathrm{p}=0,79$. The major bleeding rate in two group was similar $(1,1 \%$; in ticagrelor group v.s $2,3 \%$ in clopidogrel group), with $p$ $=0,546$. There was one cerebral hemorrhaqe event in clopidogrel aroup. We did not meet any death beacause of bleeding event in two groups. The medicine stoped rate in ticagrelor group was $12,4 \%$ v.s $17 \%$ in clopidogrel group, with OR(CI95\%) $=1,46$ $(0,63-3,38)$. Concentration of some biochemical blood parameters: creatinin, GOT, GPT, Bilirubin, glucose and heamoglobin were equal in both groups. Conclusion: The bleeding risk, the medicine stoped rate and effect on some biochemical blood parameters of ticagrelor and clopidogrel were equal in the patient with lower extremity artery disease.

\section{I. ĐĂT VẤN ĐỀ}

Bệnh động mạch chi dưới (BĐMCD) là bệnh lý xơ vữa các động mạch cấp máu cho chi dưới và các nhánh chính của nó dẫn đến giảm lượng máu tới các mô mà động mạch chi phối [1].

Người bệnh bị BĐMCD có tăng hoạt hóa tiểu cầu, tăng nguy cơ nhồi máu cơ tim, nhồi máu não và tử vong tim mạch[2]. Vì vậy dùng thuốc kháng kết tập tiểu cầu để phòng ngừa biến cố tim mạch ở những bệnh nhân bị BĐMCD là một trong các nền tảng điều trị.

Clopidogrel là thuốc kháng kết tập tiểu cầu đã được $A C C / A H A$ khuyến cáo dùng trong BĐMCD [3]. Tuy nhiên thuốc phải chuyển hóa tại gan thành dạng có tác dụng dược lý nên đột biển gene mã hóa enzym chuyển hóa thuốc CYP2C19 làm giảm hiệu quả điều trị của clopidogrel[4].

Ticagrelor là một thuốc kháng thuận nghịch thụ thể P2Y12. Uu điểm của thuốc này là không phải chuyển hóa qua gan thành dạng có tác dụng dược lý như clopidogrel[5]. Trong nghiên cứu PLATO, ticagrelor không những có hiệu quả cao hơn so với clopidogrel trong phòng ngừa biến cố tim mạch trên đối tượng bệnh nhân bi hội chứng động mạch vành cấp mà tỷ lệ các biến cố chảy máu giữa hai thuốc này cũng khác biệt không có ý nghĩa thống kê[6].

Chúng tôi tiến hành nghiên cứu này trên đối tượng bệnh nhân bị bệnh động mạch chi dưới với muc tiêu sau: So sánh tỷ lê biến cố chảy máu, tỷ lệ bỏ thuốc và ảnh hưởng trên một số chi số hóa sinh máu của ticagrelor với clopidogrel trên bệnh nhân bị bệnh động mạch chi dưới.

\section{II. ĐỐI TƯỢNG VÀ PHƯƠNG PHÁP NGHIÊN CỨU}

1. Địa điểm và thời gian nghiên cứu: Nghiên cứu được tiến hành tại Viện Tim Mạch Bênh Viên Bach Mai và Khoa Mạch Máu - Bênh Viện Chợ Rẫy từ tháng 01/2013 đến tháng 12/2016.

2. Đối tượng nghiên cứu: Nghiên cứu trên 178 bệnh nhẩn bị BĐMCD tại Viện Tim Mạch Bệnh Viện Bạch Mai và khoa mạch máu - Bệnh Viện Chợ Rẫy từ tháng 1/2013 - tháng 12/2016.

- Tiêu chuẩn lựa chọn bệnh nhân:

+ Bệnh nhân đã được chẩn đoán xác định bị BĐMCD qua siêu âm mạch máu chi dưới hay chụp MSCT động mạch chi dưới, hoặc:

+ Bệnh nhân đã được tái tưới máu chi dưới do BĐMCD.

- Tiêu chuẩn loại trừ: loại khỏi nghiên cứu những bệnh nhân có một trong những tiêu chuẩn sau: $\mathrm{Dị}$ ứng với ticagrelor hoặc clopidogrel, suy gan nặng, suy thận cần lọc máu, tiền sử xuất huyết não hoặc chảy máu nội tạng, rối loạn đông cầm máu, phải dùng thuốc kháng kết tập tiểu cầu kép hoặc thuốc kháng đông lâu dài.

\section{Phương pháp nghiên cứu:}

- Là thử nghiệm lâm sàng ngẫu nhiên có đối chứng so sánh hiệu quả điêu trị của ticagrelor với thuốc điều trị chuẩn là clopidogrel trên bệnh nhân bị BĐMCD. Bệnh nhân được phân ngẫu 
nhiên thành 2 nhóm: Nhóm nghiên cứu dùng ticagrelor $90 \mathrm{mg}$ uống 2 lần/ngày; nhóm chứng dùng clopidogrel $75 \mathrm{mg} / \mathrm{ngày}$.

- Thời gian theo dõi: 18-36 tháng: Bệnh nhân được tái khám 6 tháng 1 lần hoặc khi có biến cố.

- Tiêu chí nghiên cứu: biến cố mọi loại chảy máu; xuất huyết não; chảy máu gây tử vong; nồng độ một số chỉ số hóa sinh máu như: creatinin, GOT, GPT, bilirubin, glucose; thời gian dùng thuốc trung bình và tỷ lệ bỏ thuốc ở hai nhóm.

4. Xử lý số liệu: Phương pháp thống kê y học theo chương trình SPSS 16.0.

\section{KẾT QUẢ NGHIÊN CỨU}

Qua nghiên cứu 178 bệnh nhân bị BĐMCD chúng tôi thu được kết quả sau:

1. Một số đặc điểm chung của nhóm nghiên cứu và nhóm chứng

Bảng 1: Một số đặc điểm chung của nhóm nghiên cứu và nhóm chứng

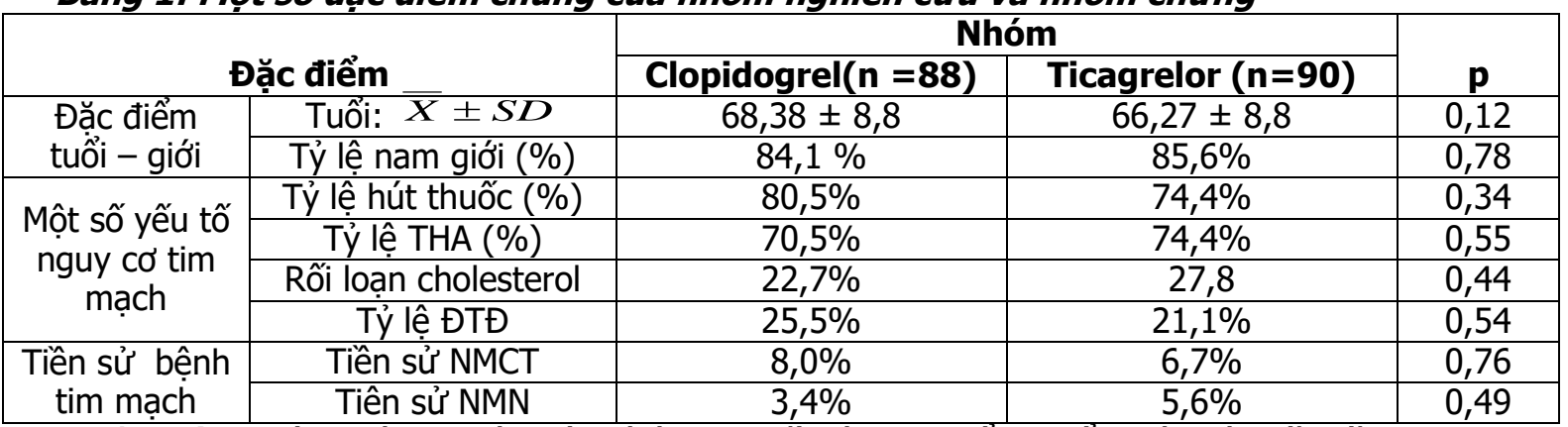

Nhận xét: Không có sự khác biệt có ý nghĩa về các đặc điểm: tuối, giới, các yếu tố nguy cơ tim mạch và tiền sử một số bệnh tim mạch giữa nhóm nghiên cứu và nhóm chứng.

2. Một số đặc điểm lâm sàng và một số chỉ số sinh hóa trước thời điểm dùng thuốc của nhóm nghiên cứu và nhóm chứng.

Bảng 2: Một số đặc điểm lâm sàng và xét nghiệm của nhóm nghiên cứu và nhóm chứng

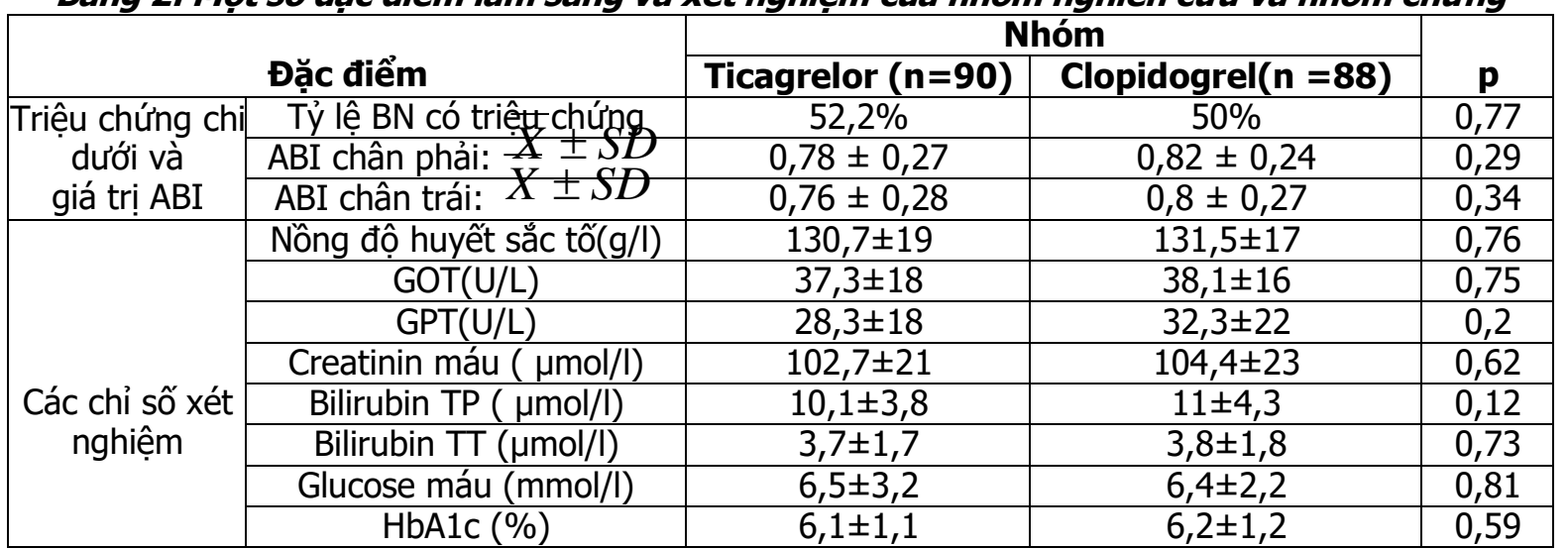

Nhận xét: Không có sự khác biệt về triệu chứng đau chi dưới, giá trị ẢBI và các chỉ số số: GOT, GPT, creatinin máu, bilirubin, glucose trước khi dùng thuốc của nhóm nghiên cứu so với nhóm chứng với $p>0,05$

3. So sánh tỷ lệ biến cố mọi loại chảy máu theo thời gian ở nhóm nghiên cứu so với nhóm chứng qua mô hình phân tích Kaplan - Meier. Biến cố mọi loại chảy máu

gồm có các loại chảy máu: chảy máu dưới da; chảy máu niêm mạc mũi, miệng; chảy máu tiêu hóa; chảy máu đường tiết niệu; chảy máu các màng tim, màng phổi, màng bụng; chảy máu não; chảy máu nội nhãn cầu; chảy máu bao khớp...Bảng dưới đầy so sánh biến cố chảy máu giữa nhóm nghiên cứu và nhóm chứng trong nghiên cứu của chúng tôi.

Bảng 3: So sánh tỷ lệ mọi loại chảy máu ở nhóm nghiên cứu và nhóm chứng

\begin{tabular}{|c|c|c|c|c|c|c|}
\hline \multirow{2}{*}{\multicolumn{2}{|c|}{ Biến số $\quad$ Nhóm }} & \multicolumn{2}{|c|}{ Ticagrelor } & \multicolumn{2}{|c|}{ Clopidogrel } & \multirow[b]{2}{*}{ p } \\
\hline & & $\mathbf{n}$ & Tỷ lệ \% & $\mathbf{n}$ & Tỷ lệ \% & \\
\hline \multirow{2}{*}{$\begin{array}{c}\text { Biến cố } \\
\text { chảy máu }\end{array}$} & Có biến cố & 7 & $7,8 \%$ & 6 & $6,8 \%$ & \multirow{2}{*}{0,79} \\
\hline & Không bị biến cố & 83 & $92,2 \%$ & 82 & $93,2 \%$ & \\
\hline
\end{tabular}




\begin{tabular}{|c|c|c|}
\hline Tống số & $100 \%$ & $100 \%$ \\
\hline $\begin{array}{l}\text { Thời gian trung bình từ khi điều trị } \\
\text { đến lúc biến cố (tháng) }\end{array}$ & $\begin{array}{l}33,8 \pm 0,9 \\
\text { (tháng) }\end{array}$ & $\begin{array}{c}34,3 \pm 0,7 \\
\text { (tháng) }\end{array}$ \\
\hline
\end{tabular}

Nhận xét: Tỷ lệ biến cố mọi loại chảy máu ở nhóm nghiên và nhóm chứng khác biệt không có ý nghĩa thống kê, với $p=0,79$.

4. So sánh tỷ lệ một số biến cố chảy máu ở nhóm nghiên cứu và nhóm chứng.

Bảng 4: So sánh tỷ lệ một số biến cố chảy máu ở nhóm nghiên cứu và nhóm chứng.

\begin{tabular}{|c|c|c|c|c|c|c|}
\hline \multirow{2}{*}{\multicolumn{2}{|c|}{ Biến cố Nhóm }} & \multicolumn{2}{|c|}{ Ticagrelor } & \multicolumn{2}{|c|}{ Clopidogrel } & \\
\hline & & $n$ & Tỷ lệ \% & $n$ & Tỷ lệ \% & \\
\hline \multirow{3}{*}{$\begin{array}{c}\text { Biến cố chảy } \\
\text { máu phải truyền } \\
\text { máu }\end{array}$} & Có biến cố & 1 & $1,1 \%$ & 2 & $2,3 \%$ & \multirow{3}{*}{$p=0,546$} \\
\hline & Không BC & 89 & $98,9 \%$ & 86 & $97,7 \%$ & \\
\hline & Tổng & 90 & $100 \%$ & 88 & $100 \%$ & \\
\hline \multirow{3}{*}{$\begin{array}{l}\text { Biến cố xuất } \\
\text { huyết não }\end{array}$} & Có BC & 0 & 0 & 1 & $1,1 \%$ & \\
\hline & Không BC & 90 & 100 & 87 & $98,9 \%$ & \\
\hline & Tống & 90 & $100 \%$ & 88 & $100 \%$ & \\
\hline \multirow{3}{*}{$\begin{array}{c}\text { Biến cố chảy } \\
\text { máu nặng gây tử } \\
\text { vong }\end{array}$} & Có BC & 0 & $0 \%$ & 0 & $0 \%$ & \\
\hline & Không BC & 90 & $100 \%$ & 88 & $100 \%$ & \\
\hline & Tổng & 90 & $100 \%$ & 88 & $100 \%$ & \\
\hline
\end{tabular}

Nhận xét: - Tỷ lệ chảy máu phải truyền máu huyết não chiếm tỷ lệ 1,1\%. Trong khi đó không ở nhóm nghiên cứu và nhóm chứng khác biệt không có ý nghĩa thống kê với OR (CI95\%) = $2,1(0,7-23)$.

- Có một bệnh nhân ở nhóm chứng bị xuất nhóm.

5. Tỷ lệ bênh nhân bỏ thuốc và thời gian dùng thuốc trung bình Bảng 5: So sánh tỷ lệ bệnh nhân bỏ thuốc ở nhóm nghiên với nhóm chứng

\begin{tabular}{|c|c|c|c|c|c|c|}
\hline \multirow{2}{*}{\multicolumn{2}{|c|}{ Biến cố $\quad$ Nhóm }} & \multicolumn{2}{|c|}{ Ticagrelor } & \multicolumn{2}{|c|}{ Clopidogrel } & \\
\hline & & $\mathbf{n}$ & Tỷ lệ \% & $\mathbf{n}$ & Tỷ lệ \% & \\
\hline \multirow{3}{*}{$\begin{array}{c}\text { Bỏ thuốc } \\
\text { điều trị }\end{array}$} & Bỏ thuốc điều trị & 11 & $12,4 \%$ & 15 & $17 \%$ & \multirow{3}{*}{$\begin{array}{c}\text { OR(CI95\%): } \\
1,46 \\
(0,63-3,38)\end{array}$} \\
\hline & Không bỏ thuốc & 78 & 87,6 & 73 & $83 \%$ & \\
\hline & Tống số & 90 & $100 \%$ & 88 & $100 \%$ & \\
\hline \multicolumn{2}{|c|}{ Thời gian dùng thuốc trung bình (tháng) } & \multicolumn{2}{|c|}{$27,8 \pm 10,5$ (tháng) } & \multicolumn{2}{|c|}{$27,8 \pm 10,1$ (tháng) } & $p=0,96$ \\
\hline
\end{tabular}

Nhân xét:

- Tỷ lệ bỏ thuốc ở nhóm nghiên cứu thấp hơn nhóm chứng. Tuy nhiên sự khác biệt là không có ý nghĩa thống kê với giá trị OR (CI95\%) là 1,46 (0,63-3,38).

- Thời gian dùng thuốc trung bình ở 2 nhóm khác biệt không có ý nghĩa thống kê, với $p=0,98$.

6. Một số chỉ số hóa sinh máu khi kết thúc điêu trị.

Bảng 6: Một số chỉ số hóa sinh ở nhóm nghiên cứu và nhóm chứng khi kêt thúc điều trị

\begin{tabular}{|c|c|c|c|}
\hline Biến số $\quad$ Nhóm & Ticagrelor & Clopidogrel & $\mathbf{p}$ \\
\hline Creatinine $(\mu \mathrm{mol} / \mathrm{l})$ & $110,7 \pm 19,5$ & $106,3 \pm 19$ & 0,28 \\
\hline $\mathrm{GOT}(\mathrm{U} / \mathrm{I})$ & $32,7 \pm 12,7$ & $34,5 \pm 14,8$ & 0,48 \\
\hline GPT(U/I) & $23,4 \pm 12,1$ & $28,6 \pm 14,5$ & 0,3 \\
\hline Bilirubin TP $(\mu \mathrm{mol} / \mathrm{l})$ & $13,1 \pm 4,6$ & $13,1 \pm 5,4$ & 0,98 \\
\hline Bilirubin TT $(\mu \mathrm{mol} / \mathrm{l})$ & $4,1 \pm 2,2$ & $4,1 \pm 2,1$ & 0,93 \\
\hline Glucose $(\mathrm{mmol} / \mathrm{l})$ & $6,2 \pm 2,6$ & $6,5 \pm 4,1$ & 0,59 \\
\hline HbA1c (\%) & $6,23 \pm 1,3$ & $5,29 \pm 1,5$ & 0,85 \\
\hline Nồng độ huyết sắc tố (gram/dl) & $136,3 \pm 17,9$ & $137,5 \pm 16,3$ & 0,7 \\
\hline
\end{tabular}

Nhân xét: Sự khác biệt về nồng độ huyết sắc tố, creatinin, GOT, GPT, bilirubin máu, đường máu, HbA1c máu sau khi điều trị bằng hai thuốc ticagrelor và clopidogrel là không có ý nghĩa thống kê với $\mathrm{p}>0,05$. 


\section{BÀN LUÂN}

1. Đặc điểm của nhóm nghiên cứu. Nghiên cứu của chúng tôi tiến hành trên 178 bênh nhân có $B \boxminus M C D$, hoăc có tiền sử can thiêp hay phẫu thuật tái tưới máu chi dưới do BĐMCD, trong đó 90 bênh nhân điều trị bằng ticagrelor và 88 bệnh nhẩn điều trị bằng clopidogrel.

Có sự tương đồng giữa nhóm nghiên cứu và nhóm chứng trong quần thể nghiên cứu của chúng tôi. Không thấy sự khác biệt có ý nghĩa thống kê về các biến số: tuổi trung bình, tỷ lệ nam giới, tỷ lệ các yếu tố nguy cơ tim mạch, tỷ lệ bệnh nhân có triệu chứng chi dưới, giá trị ABI, các chỉ số hóa sinh máu cơ bản tại thời điểm tham gia nghiên cứu giữa nhóm thuốc nghiên cứu và nhóm chứng.

2. So sánh tỷ lê các biến cố chảy máu ở nhóm nghiên cứu dùng thuốc ticagrelor so với nhóm chứng dùng thuốc clopidogrel

Kết quả nghiên cứu của chúng tôi cho thấy: Tỷ lê biến cố mọi loai chảy máu ở nhóm nghiên cứu là $7,8 \%$; ở nhóm chứng là $6,8 \%$; sự khác biệt là không có ý nghĩa thống kê với $\mathrm{OR}(\mathrm{CI} 95 \%)=0,87(0,3-2,7)$. Thời gian trung bình từ khi điều trị đến khi bị biến cố chảy máu ở nhóm nghiên cứu là $33,8 \pm 0,9$ tháng, ở nhóm chứng là 34,3 $\pm 0,7$ tháng; sự khác biệt giữa hai nhóm cũng không có ý nghĩa với $p=0,68$.

Nhóm nghiên cứu có một bệnh nhân chảy máu phải truyền máu, chiếm tỷ lệ là $1,1 \%$. Số bệnh nhân chảy máu phải truyền máu ở nhóm chứng là hai bênh nhân, chiếm tỷ lề là 2,3\%. Sự khác biệt giữa 2 nhóm là không có ý nghĩa thống kê với $\mathrm{OR}(\mathrm{CI} 95 \%)=2,1(0,7-23)$. Cả ba bệnh nhân chảy máu nặng phải truyền máu ở nhóm nghiên cứu và nhóm chứng đều là những bệnh nhân chảy máu từ dạ dày, trong đó có một bệnh nhân ung thư dạ dày ở nhóm dùng clopidogrei.

Có một bệnh nhân (chiếm tỷ lệ 1,1\%) ở nhóm chứng bị xuất huyết não. Đây là một bệnh nhân nữ tham gia nghiên cứu ở tuổi 74 . Bểnh nhân này có tiền sử đái tháo đường và tằng huyết áp trên 20 năm, với con số huyết áp tối đa $>180 / 110 \mathrm{mmHg}$. Sau 24 tháng nghiên cứu bệnh nhân được chẩn đoán xuất huyết não do THA, bệnh nhẩn quên uống thuốc điêuu trị THA. Chúng tôi không gặp bệnh nhân xuất huyết não nào ở nhóm nghiên cứu. ở cả nhóm nghiên cứu và nhóm chứng đều không có bệnh nhân nào bị tử vong vì biến cố chảy máu.

Như vậy kết quả nghiên cứu của chúng tôi cho thấy mức độ an toàn của thuốc ticagrelor so với clopidogrel trên các biến cố mọi loại chảy máu là tương đương nhau, với p > 0,05.
Kết quả so sánh biến cố chảy máu ở nhóm dùng thuốc ticagrelor so với nhóm dùng thuốc clopidogrel trong nghiên cứu PLATO trên đối tượng bệnh nhân bị hội chứng động mạch vành cấp cho thấy: tỷ lệ biến cố chảy máu nặng gây tử vong (trừ xuất huyết não) ở nhóm dùng ticagrelor thấp hơn so với nhóm dùng clopidogrel có ý nghĩa thống kê $(0,1 \%$ so với $0,3 \%$ tương ứng với $\mathrm{p}=0,03$ ). Xuất huyết não gặp nhiêu hơn ở nhóm dùng ticagrelor so với clopidogrel, tuy nhiên sự khác biệt này không có ý nghĩa thống kê $(0,2 \%$ so với $0,1 \%$ với $p=0,1)[6]$.

3. So sánh tỷ lệ bỏ thuốc điêuu trị và một số chỉ số hóa sinh máu khi kết thúc nghiển cứu ở nhóm nghiên cứu so với nhóm chứng. Nghiên cứu của chúng tôi cho thấy thời gian dùng thuốc trung bình ở 2 nhóm khác biệt không có ý nghĩa thống kê với giá trị $p=0,96$.

Nhóm nghiên cứu có 11 bệnh nhân bỏ thuốc điều trị chiếm 12,4\%. Nhóm chứng có 15 bệnh nhân bỏ thuốc chiếm $17 \%$. Một số nguyên nhân bỏ thuốc điều trị mà chúng tôi khai thác được là: bệnh nhân cao tuổi ở các tỉnh xa không đển tái khám và lĩnh thuốc được nên bệnh nhân tự ý bỏ thuốc, hoặc do bệnh nhân bị biến cố chảy máu, hoặc biển cố khác và bỏ thuốc điều trị. Kết quả nghiên cứu của chúng tôi cho thấy mặc dù tỷ lệ bỏ thuốc ở nhóm nghiên cứu thấp hơn nhóm chứng, tuy nhiên sự khác biệt là không có ý nghĩa thống kê với OR(CI95\%) là 1,46 (0,63$3,38)$. Kết quả so sánh về thời gian dùng thuốc trung bình của hai nhóm cũng không có sự khác biệt với $p=0,96$.

Tại thời điểm kết thúc nghiên cứu các chỉ số hóa sinh máu như: ure, creatinin, GOT, GPT, Bilirubin, Glucose, HbA1C, heamoglobin ở hai nhóm khác biệt không có ý nghĩa thống kê, với p $>0,05$. Khi so sánh về thay đổi các chỉ số hóa sinh máu khi điều trị trong nghiên cứu PLATO chỉ thấy mức tăng creatinin trên $50 \%$ ở nhóm ticagrelor cao hơn clopidogrel $(7,4 \%$ và $5,9 \%$ tương ứng). Tuy nhiên mức tăng này thường không tăng thêm khi tiếp tục dùng thuốc và tổn thương thận mức độ nặng không khác biệt giữa hai nhóm[6].

\section{KẾT LUÂ̂N}

Nguy cơ chảy máu, tỷ lệ bỏ thuốc và ảnh hưởng trên nồng độ một số chỉ số hóa sinh máu của ticagrelor tương đương với clopidogrel trên bệnh nhân bị bệnh động mạch chi dưới.

\section{TÀI LIÊU THAM KHẢO}

1. Hiatt W.R, Goldstone J, Smith $S$ et al (2008). Atherosclerotic Peripheral Vascular 
Disease Symposium II: nomenclature for vascular diseases. Circulation, 118(25), 2826-9.

2. Pande R. L, Perlstein T. S, Beckman A et al (2011). Secondary prevention and mortality in peripheral artery disease: National Health and Nutrition Examination Study, 1999 to 2004. Circulation, 124(1), 17-23.

3. Hirsch A. T, Criqui M. $H$ et al (2001). Peripheral arterial disease detection, awareness, and treatment in primary care. Jama, 286(11), 1317-24.

4. Mega J.L, Simon T, Collet J.P et al (2010).
Reduced-function CYP2C19 genotype and risk of adverse clinical outcomes amona patients treated with clopidoarel predominantly for PCI: ametaanalysis. JAMA, 304(16), 1821-1830.

5. Teng R, Oliver S, Hayes MA, Butler K (2010). Absorption, distribution, metabolism and excretion of ticagrelor in healthy subjects. Drug Metab Dispos, 38,1514-21.

6. Wallentin L, Becker R.C et al (2009). Ticagrelor versus clopidogrel in patients with acute coronary syndromes. N Engl J Med, 361(11), 1045-57.

\section{ĐĂC ĐIỂM LÂM SÀNG, CÂN LÂM SÀNG VÀ CHẨN ĐOÁN HÌNH ẢNH BÊ̂NH NHÂN MÁU TƯ DƯớI MÀNG CỨNG MẠN TÍNH ĐƯỢC ĐIÊU TRI PHẪU THUÂTT TẠI BỆNH VIỆN VIỆT ĐỨC TỪ 2017-2018}

\section{TÓM TẮT}

Mục tiêu: mô tả các đặc điểm dịch tễ hoc, lâm sàng, xét nghiệm và chẩn đoán hình ảnh của bệnh lý máu tụ dưới màng cứng mạn tính. Đối tượng và phương pháp nghiên cứu: nghiên cứu mô tả, hồi cứu 91 trường hợp máu tu dưới màng cứng man tính đã được chẩn đoán và điều trị phẫu thuât tại bênh viên Viêt Đức từ 1.2017 đến 6.2018. Kết quả: tuổi trung bình $(59,26 \pm 1,86)$; tỉ lệ nữ $(19,78 \%)$; nguyên nhân chấn thương so não $(72,53 \%)$; thời gian từ khi có nguyên nhân đến khi được chẩn đoán $(33,23 \pm 2,54$ ngày); có $87,91 \%$ số bệnh nhân có điểm GCS $\geq 13$; Đau đâuu là triệu chứng thường gặp nhất $(73,63 \%)$; Không có sự khác biệt có ý nghĩa thống kê về bên chứa máu tụ; độ dày lớn nhất của khối máu tụ là $18,27 \pm 0,688$ (mm). Kết luân: Máu tụ dưới màng cứng mạn tính chủ yếu ở nhóm người trẻ (dưới 60 ), nam nhiều hơn nữ; nguyên nhân chủ yếu là chấn thương sọ não.

\section{SUMMARY}

\section{A STUDY OF CLINICAL, LABORATORY AND IMANGING CHARACTERISTICS OF CHRONIC SUBDURAL HEMATOMA \\ PATIENTS TREATED BY SURGERY AT VIET-} DUC HOSPITAL FROM 2017 TO 2018

Objective: Decriber the epidemiology, clinical, laboratory and imaing characteristics of chronic subdural hematoma. Patients and methods: A cross-section, descriptive and retrospective study with 91 patients who were diagnosed, surgically treated of chronic subdural hematoma at Viet-Duc hospital from Jan 2017 to June 2018. Results: mean age

\section{*Bênhh viện Việt Đức}

Chiu trách nhiệm chính: Ngô Manh Hùng

Email: ngomanhhung2000@gmail.com

Ngày nhận bài: 6.01.2021

Ngày phản biện khoa học: 26.2.2021

Ngày duyệt bài: 10.3.2021
Ngô Mạnh Hùng*

$(59.26 \pm 1.86)$; female ratio $(19.78 \%)$; brain trauma injury $(72.53 \%)$; onset from cause to diagnosis (33.23 2.54 days); $87.91 \%$ of patients had GCS $\geq 13$ Headache was the most common symptom $(73.63 \%)$; there was no significant difference between the side of hematoma. The mean of largest thickness of hematoma was $18.27 \pm 0.688(\mathrm{~mm})$. Conclusion: Chronic subdural hematoma revealed common in the patients who were under 60 years old; male predominance; the most common cause was brain trauma.

\section{I. ĐẶT VẤN ĐỀ}

Máu tụ dưới màng cứng man tính (CSDH: chronic subdural hematoma) là bệnh lý phổ biến nhất trong phẫu thuật thần kinh [1], gặp nhiều ở người cao tuổi với tần suất găp là khoảng 58 bệnh nhân/100.000 dân tuổi trên 70 [2]. Bênh được mô tả đầu tiên bởi Virchow năm 1857, mặc dù có rất nhiều phương pháp điều trị, cả nội khoa và ngoai khoa, được đưa ra, tuy nhiên kểt quả điều trị còn rất khác nhau giữa các tác giả. Hiện nay, cùng với sự thay đổi về điều kiện kinh tế xã hội, có nhiều yếu tố ảnh hưởng đến các đăc điểm về dịch tễ hoc, nguyên nhân sinh bênh cũng như các bênh lý kèm theo trong máu tu dưới màng cứng mạn tính, khiến cho việc cập nhật những số liệu là cần thiết. Vì vậy, nghiển cứu được tiến hành nhằm mô tả đăc điểm dich tễ, lâm sàng, xét nghiệm và chẩn đoán hình ảnh của bệnh nhân máu tụ dưới màng cứng mạn tính được điều trị phẫu thuật tại bệnh viện Việt Đức từ 1.2017 đển 6.2018 .

\section{II. ĐỐI TƯỢNG VÀ PHƯƠNG PHÁP NGHIÊN CứU}

Nghiên cứu mô tả, cắt ngang nhóm bệnh nhân được chẩn đoán và điều trị phẫu thuật máu tụ dưới màng cứng mạn tính tại bệnh viện Việt Đức từ 1.2017 đến 6.2018 